alternativas. El lenguaje se requiere para explicar las técnicas a los estudiantes y a los compañeros, que necesitan amplitud de mente para aceptar las nuevas técnicas, estilos, aplicaciones, etc. Ciertamente, los estudiantes verán con el tiempo la belleza en estas técnicas. Sobre todo esto, los estudiantes aprenderán también a cooperar por un beneficio mutuo y desarrollarán virtudes tales como el coraje, honestidad, ecuanimidad y generosidad. Estas virtudes no serán puramente intelectuales, pero casan bien con la actividad física. La idea de Kano es que estas habilidades y virtudes no son útiles únicamente en la sala de entrenamiento, sino que también funcionan en el día a día. Efectivamente, Kano cree que el combate sólo es el primer nivel del judo. El segundo nivel es un cuerpo y una mente sana, y el tercer nivel es la contribución a la sociedad, para lo que son esenciales un cuerpo y mente robustos. Así, el judo fue diseñado para darnos salud corporal, agudeza mental y hábitos virtuosos para ayudar al desarrollo de nuestras sociedades.

Por supuesto, como muchas otras artes marciales japonesas, el judo se ha transformado en deporte, y en un deporte Olímpico. Mientras que esto produce excelentes atletas e inspira a generaciones de estudiantes por todo el mundo, también tiene una influencia corruptora. Para Kano esto se debe a que entrenar para ganar compromete el espíritu de amplitud de mente en la enseñanza y en el aprendizaje -los estudiantes entrenan "la" técnica letal, "la" táctica ganadora, etc.-. Esto lleva a la estrechez y al empecinamiento, mientras que el judo debe dirigirse hacia la amplitud de mente y a la flexibilidad. Asimismo, puede producir obsesión con la fama y la riqueza, que nuca deberían ser perseguidas como fin en sí mismas. Los atletas mejor pagados de hoy seguramente tienen conciencia de estos riesgos, así como de los dudosos rasgos personales que los acompañan -hemos oído muchas historias de riñas, ingratitud, de hombres y mujeres deportistas de mal carácter como para pensar lo contrario [de lo positivo del deporte]-. Las razones de Kano para creer que el auténtico judo está por encima de las trampas del deporte y la comercialización era que era un cami- no de vida, y no simplemente un juego. En sus palabras, "el judo no es simplemente un arte marcial sino más bien el principio básico del comportamiento humano" (p. 77). Este principio de "mejor uso de la propia energía", junto con la otra máxima fundacional del judo, "beneficio mutuo", es lo que le coloca lejos de muchos otros deportes y de muchas de las artes marciales ultra violentas. En este sentido, Mind Over Muscle no es solamente una excelente fuente de información sobre una de las mayores historias de éxito del s. XX, sino que también se proyecta como una guía educativa para la vida.

Desde luego, también hay defectos. Como resultado de las muchas conferencias y publicaciones de Kano, Mind Over Muscle es muy repetitivo. A pesar de la claridad y simplicidad de su escritura -y de la sensata traducción de Ross-, el libro podría haber sido un poco más breve, quizá para dejar espacio a otros escritos, ilustraciones o fotografías. Asimismo, algunas de los comentarios positivos de Kano parecen muy pasados de moda, por ejemplo su indulgente aprobación de los principios de eficiencia detrás del Taylorismo en los Estados Unidos parecen alegremente despreocupados de los peligros que esta forma de organización plantearía globalmente. En una visión retrospectiva, la "eficiencia" de Taylor es absolutamente antiética al espíritu del judo. Algunas de las anécdotas de Kano -por ejemplo sobre Moshe Feldenkrais o el luchador Americano Dalue- parecen particularmente condescendientes, quizá como resultado de la aproximación pedagógica de Kano a las cosas. Finalmente, está el problema común a todos los libros de artes marciales: al final del día lo haces o no lo haces. No hay cantidad de lectura que pueda reemplazar el entrenamiento real y su aplicación realista.

Si bien, en conjunto, esta es una excelente introducción a las ideas en las que se basa el judo y a las contribuciones positivas que las artes marciales como el judo pueden hacer a los individuos y a las sociedades. Representa los genuinos intentos de Kano para casar las artes de combate con la educación física, y con un ethos de cooperación, altruismo y desarrollo personal. Para cualquier persona interesada en leer sobre estos asuntos, o simplemente sobre el origen de una de las primeras artes marciales de Japón, Mind Over Muscle es un excelente título para su biblioteca particular.

\section{Chinese Martial Arts Training Manuals: A Historical Survey}

Por Brian Kennedy and Elizabeth Guo Berkeley, CA: North Atlantic Books, 2005

328 páginas. $15,2 \times 20,3 \mathrm{~cm}$.

Ilustraciones

I.S.B.N.: $1-55643-557-6 \bullet \$ 19.95$

Idioma: Inglés.

Disponible en:

North Atlantic Books/Frog, Ltd.

P.O. Box 12327

Berkeley, CA 94712

Telf.: +1 800.337.2665

Fax: +1 510.559.8279

Email:orders@northatlanticbooks.com www.northatlanticbooks.com

\section{Revision por Nyle C. Monday}

No es habitual que buscador casual en la sección de artes marciales de una librería se encuentre con algo verdaderamente único. Mientras que algunos autores han sido capaces de romper con el formato de libros de "como hacer", la gran mayoría de obras publicadas todavía se ocupan de los aspectos técnicos de uno u otro estilo. Sin duda, la razón de esto es la gran demanda de este tipo de libros. Esto hace que sea un placer aún mayor cuando algo diferente a lo habitual aparece en la estantería, ofreciendo llevar al lector en un viaje que él o ella no ha hecho nunca, o aproximándole a un tema que quizá nadie en el pasado ha considerado estudiar. Esta es realmente la situación en el caso del nuevo libro de Brian Kennedy y Elizabeth Guo Chinese Martial Arts Training Manuals: A Historical Survey.

Para empezar con esta revisión, puede ser bueno para este revisor confesar que padece un caso avanzado de bibliomanía. Parafraseando a Will Rogers, nunca ha encontrado un libro que no le guste, al menos hasta cierto 
punto. Sus abusos en las tiendas de libros son tales que la gente en algunos lugares de la China continental no dudan en seguir hablando del loco americano que, hace veinte años, entró en su librería y compró una copia de cada uno de los libros de artes marciales que tenían en las estanterías. El tiempo y el dinero han reducido estos hábitos de gasto en cierta manera, y sus gustos se has hecho más precisos, pero pocas cosas harán que gaste su presupuesto para libros tan rápido como algo nuevo y fuera de lo común. Este volumen ciertamente cumple con la factura. En un nivel, es un libro sobre libros, y no obstante su propósito va más allá de eso. Es, en efecto, una historiografía de las artes marciales chinas y de las obras publicadas que han ayudado a preservarlas.

En su introducción los autores establecen sus metas tales como: 1) Introducir los manuales de entrenamiento tradicionales a la audiencia de habla inglesa, y 2) "Ubicar las artes marciales chinas en un contexto histórico y social más realista" (p. xv). Se aproximan a esta labor realizando en primer lugar una discusión general sobre estos manuales de entrenamiento, y después examinando en detalle algunos ejemplos específicos. Mientras que esto suena como muy concreto, los autores realmente van mucho más allá de lo que uno pudiera pensar en principio, especialmente en términos de lo que puede ser considerado como una "discusión general".

Los autores comienzan con una perspectiva general sobre las artes marciales chinas, incluyendo definiciones de las ideas de "sistemas" y "estilos" que de algún modo tienen reminiscencias de las obras de Donn Draeger sobre las artes japonesas. Los orígenes de los nombres, provenientes de los principios fundamentales representativos del arte, la familia fundadora o el lugar de origen, y a veces la fuente o denominaciones similares que se desarrollaron en Japón. También se relacionan brevemente las metas y métodos de práctica de estas artes. Incluso se discutes temas exóticos como el Sistema Imperial de Examen, la romanización de los nombres chinos y los retos a los que se han enfrentado aquellos que intentan traducir estos manuales al inglés. Este último tema le sonará a cualquiera que haya tratado de traducir material en chino o japonés, especialmente en un tema tan esotérico como son las artes marciales.

Sin embargo, los autores no perdonan fácilmente a la comunidad de artes marciales chinas. De hecho, después de enmarcar cuatro definiciones o usos muy diferentes del concepto de Qi/Chi, hacen la afirmación de que realmente el "fraude, charlatanismo, incompetencia e ignorancia prevalecen en las artes marciales" (p. 31). Esta puede ser una afirmación irritante, no obstante los autores declaran pronto que su meta es ver las artes marciales chinas de un modo realista, sin las ensoñaciones y fantasías distorsionantes que tiene mucho de lo que llega al público. Efectivamente, en la primera mitad del libro los autores "ponen a descansar" sistemáticamente dicotomías tan habituales como son artes internas / externas, Shaolin (Budista) / Wudang (Taoísta), y del sur (piernas) / norte (manos) que han sido durante mucho tiempo "de dominio público”. Muchos de estos conceptos son realmente desarrollos bastante recientes, que serán una sorpresa para muchos lectores. La mejor aproximación, parece que dicen los autores, es aceptar el hecho de que, aunque algunos individuos hayan desarrollado habilidades que realmente causen asombro, son el resultado de los cuatro puntos clave de las artes marciales -condición física, base técnica práctica, conjuntos de rutinas y combatemás que la posesión de un arma mágica o de una técnica secreta dejada en herencia por un maestro místico.

Cubriendo la historia de las artes marciales chinas, los autores señalan un punto de inflexión en la actitud pública a partir de la Revolución de 1911. Al contrario de la situación de Japón, los chinos tenían a los guerreros en muy baja estima, como ilustra el concepto tradicional de que "no usas buen acero para los clavos, y no usas buenos hombres como soldados". Aunque esto se compensaba hasta cierto punto con historias populares como Outlaws of the Marsh [Forajidos del pantano], las prácticas marciales eran generalmente patrimonio de las clases bajas y parecían un tanto minusvaloradas por la clase culta que condujo
China a lo largo del sistema de exámenes basado en el Confucianismo. Esto cambió cuando se fundó la república, poniendo punto final a la dominación extranjera de los manchúes. De pronto, practicar las artes marciales llegó a ser motivo de orgullo y una actividad muy nacionalista, y esta idea fue apoyada por el nuevo gobierno, de manera más significativa por el fundador de la Academia Central de Guoshu en 1927. Los autores consideran a la etapa siguiente como la época dorada de los manuales de entrenamiento.

Se dedica una sección de este libro a los historiadores que publicaron estos manuales de entrenamiento, así como a los estudiantes extranjeros (como Robert Smith) que han hecho mucho para llevar estos materiales al alcance de los lectores no chinos. La manera en que muchos de estos manuales fueron reciclados, a veces (si no a menudo) sin permiso del autor original, pone de relieve la diferencia entre los conceptos chino y americano de propiedad (p. ej. copyright). En China, volver a publicar el trabajo de otro era visto como un honor para el autor, más que un robo. Consecuentemente se pueden encontrar varios manuales diferentes, algunos con diferentes autores, esencialmente con los mismos contenidos. Esto, ciertamente, explica las "similitudes" entre textos con las que se ha encontrado este revisor a lo largo de los años.

Escondidos, también en la primera mitad del libro, hay tesoros escondidos tales como una historia marcial de Taiwan, cómo se las arreglaban los artistas marciales para lograr sobrevivir, e incluso un breve capítulo sobre Liu Kang-yi, fundador de Lion Books Martial Arts Publishing de Taiwan, así como editor de Taiwan Wu Lin, una de las mejores revistas de artes marciales publicadas en esa nación. El Sr. Lui empezó como coleccionista de manuales de artes marciales, pero con el tiempo fundó su propia compañía de publicaciones para ayudar a preservar y difundir el conocimiento que se desprendía de ellas. Una cosa que este revisor encuentra curiosa, sin embargo, es la omisión de la dirección de Lion Books en Taiwan. Aunque muchos de los manuales reimpresos por esta editorial son distribuidos en los EE.UU. por 
Plum Publications of Santa Cruz, CA, hubiera estado bien incluir la dirección en Taiwan en un apéndice para aquellos lectores a los que les gustaría contactar con el Sr. Liu directamente.

La segunda mitad del libro se dedica a autores específicos y a los manuales que elaboraron, y cubre un intervalo de años desde 1500 hasta los tiempos modernos. Se incluyen sobre 33 autores, muchos de ellos con varias obras. Se ofrece para cada autor alguna historia de vida, incluyendo sus credenciales marciales así como información relativa a las historia de la publicación de sus libros. Esto demuestra que la obra es un gran regalo para aquellos de nosotros que hemos coleccionado estos manuales a lo largo de los años pero que no conocíamos mucho de los hombres que los escribieron. Algunos de los nombres serán familiares para los lectores con experiencias en las artes chinas, pero otros -algunos de los cuales eran grandes nombres en su época- serán menos conocidos. Sobre todo, estos ensayos proporcionan una excelente introducción a un amplio abanico de manuales de una variada selección de autores.

Kennedy y Guo han hecho un gran favor a la comunidad de artes marciales elaborando este libro. Han escrito un libro que será realmente útil tanto a principiantes como a practicantes avanzados. Su sensata aproximación no sentará bien a aquellos que quieren creer gran parte de la versión de la historia de las artes marciales chinas que presentan los Chop Socky [películas de peleas de kung-fu] o Kwai Chan Caine [el protagonista de la famosa serie televisiva Kung Fu, encarnado por David Carradine], y algunos practicantes más serios pueden discutir sobre ciertos aspectos, pero, sobre todo, para aquellos que quieren una visión acertada del desarrollo de las artes marciales desde una perspectiva histórica, este es ciertamente un libro muy valioso.

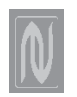

\section{Progressive Aikido: The Essential Elements}

Por Moriteru Ueshiba

Traducido por John Stevens

Tokyo: Kodansha International, 2005

195 páginas 20,3×25,4 cm.

Ilustraciones.

I.S.B.N.: 47-7002-172-0 $\$ 35.00$

Idioma: Inglés

Disponible en:

North Atlantic Books/Frog, Ltd.

P.O. Box 12327

Berkeley, CA 94712

Telf.: +1 800.337.2665

Fax: +1 510.559.8279

Email:

orders@northatlanticbooks.com

www.northatlanticbooks.com

Revisión por Guillermo Paz-y-Miño C. y Avelina Espinosa

Ueshiba nos ofrece en esta obra una aproximación enciclopédica y generosa al aikido tradicional. El libro es una guía gráfica y progresiva a las artes básicas del aiki donde el aikido es descrito como un arte marcial, un método de entrenamiento para el desarrollo mental y corporal, una táctica de autodefensa para la vida cotidiana, un reto físico y mental para el autoperfeccionamiento y como una alternativa de educación a largo plazo. El autor pone los ojos en el espíritu del lector esperando realizar primero una comunicación sobre filosofía y luego sobre aspectos físicos. La unificación de la intención mental con la acción física es el objetivo de las enseñanzas que se discuten en este útil volumen.

En último término el aikido es la armonización del $k i$, según señala el autor. "Ki es la energía vital del universo y la sutil función del ki anima los cinco sentidos. Emplea esa fuerza, con la unidad del cuerpo y la mente, y te podrás mover libre como desees", escribe Ueshiba. Y continúa aconsejándonos que evitemos los conflictos, comprendamos los patrones del movimiento y aceptemos las técnicas honrando la sofisticación del arte. Esto no debe ser confundido con poderes irreales de imposible existencia, sino como un lógico resultado final de la proyección de la anatomía humana en un mundo material y dinámico.

Sin embargo, si uno quiere tener este libro como compañero de aprendizaje es crucial capturar la verdadera intención del autor cuando lo compiló.

Ueshiba nos anima a "adquirir" el aikido estudiándolo con paciencia. Camina con el lector paso a paso, como dándole seguridad en su camino hacia el progreso y, optimistamente, hacia la perfección. El libro de Ueshiba nos hace sentirnos seguros, guiados y optimistas sobre nuestro futuro como practicantes del arte.

El libro es progresivo no sólo en su formato, que incluye mensajes crecientemente complejos tanto en el texto como en las fotografías, sino también en su contenido teórico que culmina en una apabullante exposición de la versatilidad de aikido. Si nuestra decisión es seguir este libro con disciplina, nos estaremos comprometiendo a años de entrenamiento antes de ser capaces de seguir con otro libro.

Se presentan con un detalle exquisito técnicas desde la posición de pie, formas de rodar, caídas, formas de caminar y técnicas de seguir o dirigir. Enriquecen el texto cientos de fotografías que son primeros planos, las cuales son normalmente precisas y suficientes como para comunicar tanto las rutinas básicas como avanzadas. El autor enfatiza las técnicas de muñeca, los ataques con la mano abierta, algunos agarres, inmovilizaciones y algunas proyecciones con dos atacantes. Se dedica una sección completa al tanto o cuchillo, particularmente a inmovilizaciones. El libro finaliza con la etiqueta y algunos métodos adicionales de entrenamiento, incluyendo saludos, forma de estar de pie y sentarse, ejercicios y estiramientos de calentamiento [o vuelta a la calma], habitualmente ubicados al principio de la mayoría de los libros. La intención es elocuente: el aikido comienza y finaliza con la calma. Es muy fácil olvidar que en este arte la pausa es la necesaria antítesis del movimiento, y que un exacto equilibrio entre pausa y el movimiento es lo que define al aikido.

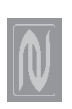

